\title{
Structure-based survey of ligand binding in the human insulin receptor
}

\author{
Judith Klein-Seetharaman ${ }^{1}$, Whitney Vizgaudis ${ }^{1}$, and Lokender Kumar ${ }^{1}$ \\ ${ }^{1}$ Colorado School of Mines
}

May 31, 2021

\begin{abstract}
The insulin receptor is a membrane protein responsible for regulation of nutrient balance and therefore an attractive target in the treatment of diabetes and metabolic syndrome. Pharmacology of the insulin receptor involves two distinct mechanisms, (1) activation of the receptor by insulin mimetics that bind in the extracellular domain and (2) inhibition of the receptor tyrosine kinase enzymatic activity in the cytoplasmic domain. While a complete structural picture of the full-length receptor comprising the entire sequence covering extracellular, transmembrane, juxtamembrane and cytoplasmic domains is still elusive, recent progress through cryoelectron microscopy has made it possible to describe the initial insulin ligand binding events at atomistic detail. We utilize this opportunity to obtain structural insights into the pharmacology of the insulin receptor. To this end, we conducted a comprehensive docking study of known ligands to the new structures of the receptor. Through this approach, we provide an in-depth, structure-based review of human insulin receptor pharmacology in light of the new structures.
\end{abstract}

\section{Hosted file}

HUMAN Insulin .docx available at https://authorea.com/users/416880/articles/524242-structurebased-survey-of-ligand-binding-in-the-human-insulin-receptor 